\title{
Season-specific management strategies for rainfed soybean in the South American Pampas based on a seasonal precipitation forecast
}

\author{
Gonzalo Rizzo $^{\mathrm{a}, *, 1}$, Sebastian R. Mazzilli ${ }^{\mathrm{a}}$, Oswaldo Ernst ${ }^{\mathrm{a}}$, Walter E. Baethgen ${ }^{\mathrm{b}}$, \\ Andres G. Berger ${ }^{c}$ \\ ${ }^{a}$ Departamento de Producción Vegetal, Facultad de Agronomía, Estación Experimental Mario Alberto Cassinoni, Universidad de la República, Paysandú 60000, Uruguay \\ ${ }^{\mathrm{b}}$ International Research Institute for Climate and Society (IRI), Columbia University, 61 Route 9W, 9 Palisades, NY 10964, USA \\ ${ }^{\mathrm{c}}$ Instituto Nacional de Investigación Agropecuaria (INIA), Programa de Cultivos de Secano, Estación Experimental INIA La Estanzuela, Ruta 50 km 11 , Colonia 70006, \\ Uruguay
}

\section{H I G H L I G H T S}

- IRI seasonal forecasts successfully forecasted precipitation scenarios in the region.

- Forecast success was higher for below (77\%) than for above normal $(60 \%)$ precipitation.

- Dominant farmer management practices are aligned with a risk-averse strategy.

- Season-specific management could increase soybean yield between 0.6 and $1.6 \mathrm{Mg} \mathrm{ha}^{-1}$.

\section{G R A P H I C A L A B S T R A C T}

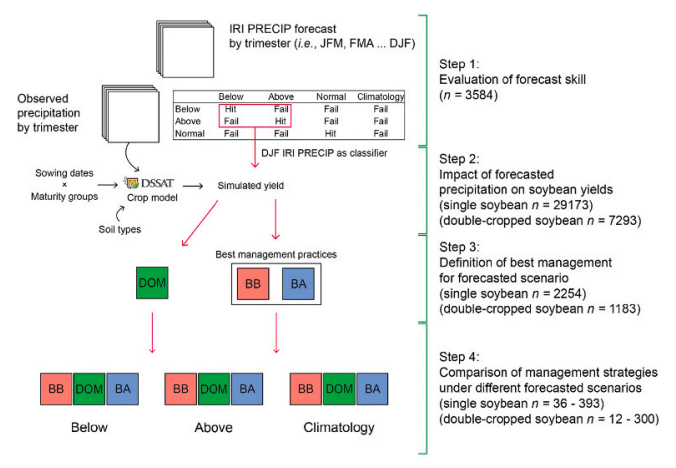

\section{A B S T R A C T}

CONTEXT

Global climate change is resulting in more frequent and more damaging extreme events affecting the performance of production systems. It is imperative to develop good season-specific crop management recommendations to help farmers to improve their adaptive capacity to a changing climate one season at a time. OBJECTIVE: We aimed to evaluate the skill of the International Research Institute for Climate and Society (IRI) seasonal precipitation forecasts and the interaction between the forecasted seasonal precipitation scenarios and management practices for rainfed soybean cropping systems using a crop simulation model.

METHODS: We used a crop simulation model (CROPGRO-Soybean) coupled with weather data to assess the potential use of the IRI seasonal precipitation forecasts as a tool to optimize season-specific management strategies for rainfed soybean in Uruguay. We used a total of 620-668 IRI seasonal precipitation forecasts released from 2003 to 2016 for each of the five weather stations located in the main soybean producing area. The analysis was performed for two soybean cropping systems (i.e., sown as a single crop or as double-cropped soybean), for

\footnotetext{
* Corresponding author.

E-mail address: grizzo2@huskers.unl.edu (G. Rizzo).

1 Current address: Department of Agronomy and Horticulture, University of Nebraska-Lincoln, Lincoln, NE 68583-0915, USA
} 
which we considered combinations of sowing dates and maturity groups (11 sowing dates $\times 3$ maturity groups combinations for each soybean cropping system).

RESULTS AND CONCLUSIONS: The IRI seasonal precipitation forecasts were able to successfully forecast belownormal precipitation scenarios in $77 \%$ of the total predictions developed for this scenario considering all weather stations during the study period (2003-2016), while it was less accurate in forecasting above-normal precipitation scenarios ( $60 \%$ of success). We found that earlier sowing dates were a better strategy for years when an above-normal precipitation forecast was released for the December-January-February period $\left(4.7 \mathrm{Mg}^{\mathrm{ha}}{ }^{-1}\right.$ average seed yield). In contrast, delayed sowing dates were more appropriate for below-normal precipitation forecasts (3.7 $\mathrm{Mg} \mathrm{ha}^{-1}$ average seed yield). Applying season-specific management practices farmers could potentially increase their soybean yields by up to 0.6 and $1.6 \mathrm{Mg} \mathrm{ha}^{-1}$, in years with below- or above-normal forecasted precipitations, respectively. The benefit of season-specific management will depend on the interaction among all management practices, the effective capacity of farmers to implement it, and the risk profile the farmer adopts and it is exposed to.

SIGNIFICANCE: Here we built a novel approach to assess the impact of considering seasonal precipitation forecasts for optimizing crop production. This assessment provided insights on how farmers can use seasonal precipitation forecasts to optimize rainfed soybean yield for a specific cropping season.

\section{Introduction}

Increasing grain yield production of dryland cropping systems could contribute up to $c a .46 \%$ of the projected future food supply/demand gap by 2050 (Garnett et al., 2013; Godfray and Garnett, 2014; Keating et al., 2014). However, global climate change trends and interannual rainfall variability force producers to design specific crop management decisions under uncertain weather conditions (Carleton and Hsiang, 2016; Liang et al., 2017). Worldwide trends of temperature increase and the higher occurrence frequency of heatwaves have lowered maize and wheat yields (Lobell and Field, 2007), causing annual losses of US\$ 5 billion in grain production (Lobell et al., 2011). Likewise, this trend in temperature has negatively impacted crop yields in South America (Tito et al., 2018). However, knowing that the global temperature will continue to increase does not tell us what the temperature characteristics of any specific growing season will be, which is what farmers need in order to make decisions every year. IPCC's report confirms that global climate change is resulting in more frequent and more damaging extreme events, which clearly affect the performance of production systems. That is why it is imperative to develop good season-specific crop management recommendations. Here, we would be helping farmers to improve their adaptive capacity to a changing climate by improving it one season at a time.

The El Niño/Southern Oscillation (ENSO) is an ocean-atmospheric phenomenon that have been related to agricultural production variability (Cane et al., 1994; Hammer et al., 2001; Podestá et al., 2002) as it is accepted that it can affect climate patterns and crop yields in both, the southern (Fraisse et al., 2008), and northern hemisphere (Baigorria et al., 2008; Hollinger et al., 2001; Martinez and Jones, 2011). The phenomenon has three phases (El Niño, La Niña, and Neutral) and each ENSO phase affects weather conditions in SE South America in different ways. The El Niño phase increases the chances of wetter than normal austral spring and early summer (Lenssen et al., 2020; https://iri. columbia.edu/news/new-data-and-tools-bring-a-deeper-understa nding-of-el-nino/) and the La Niña phase increases the probability of cooler than normal austral summer months and drier than normal late austral winter and spring (August to December) weather conditions. The sea surface temperature in the El Niño region can be forecasted with a 3-9 months lead time. These ENSO forecasts in turn are used in climate models to produce seasonal climate (temperature and precipitation) forecasts. One of the most widely used seasonal climate forecasts is produced by the International Research Institute for Climate and Society (IRI), which has been releasing global seasonal climate forecasts since 1997. IRI seasonal climate forecasts are probabilistic, and have shown good predictability of the seasonal precipitation patterns in SE South America, Eastern USA, Indonesia, Australia, Eastern Africa (Barnston et al., 2003; Goddard et al., 2003), which makes this forecast a promising tool for supporting farmers' management decisions in those regions. The seasonal climate forecasts become particularly useful when combined with crop modeling due to the ability of crop models to capture the climate - soil - crop interactions determining the crop yield (Crane et al., 2010; Hammer et al., 2014; Potgieter et al., 2003).

Management decisions that farmers adopt to improve adaptation to climate variability have a direct impact on yields. Risk-averse farmers tend to follow conservative management strategies that reduce yield variability but penalize yield potential (Monjardino et al., 2013). Riskneutral farmers tend to choose management options that are optimal for average seasons but are sub-optimal for either favorable or unfavorable seasons (Meza et al., 2008). In rainfed soybean cropping systems in the South American Pampas, the most important yield-limiting factor is the total rainfall and its distribution during the cropping season (Calviño and Sadras, 1999; Rizzo et al., 2021). Prior to the sowing date, which is one of the most yield-determining agronomic management decisions (Rattalino Edreira et al., 2017; Vitantonio-Mazzini et al., 2021), skillful probabilistic seasonal climate forecasts can provide information about expected rainfall in the growing season. Although several studies have documented the effect of the ENSO in the soybean yields in the South American Pampas (Araneda-Cabrera et al., 2021; Monzon et al., 2007), there is a lack of knowledge about the ability of probabilistic seasonal forecasts to support farmers management decisions and to optimize the agronomic management practices for each season (Bert et al., 2007).

Since Uruguay is located in a region that is strongly influenced by ENSO (Landman et al., 2019), it provides a good opportunity to assess the use of seasonal climate forecasts (which are issued on a monthly basis) as a tool that can help to improve farmers management decisions. Our hypothesis is that seasonal precipitation forecasts can be a useful tool to optimize grain yield, since they can produce an outlook of expected precipitation during the critical period for soybean seed yield setting (Giménez, 2007) with enough time before sowing to allow taking specific agronomic management decisions. Although previous studies have evaluated the effect of ENSO phases on management practices for several crops and regions, to our knowledge this is the first attempt to evaluate a season forecasting tool and its interaction with management practices. For this purpose, we used a validated crop simulation model, coupled with high-quality weather, soil, and crop management data, under the South American Pampas agro-ecological conditions. Specific objectives were: (i) to assess the skill of the IRI seasonal precipitation forecast in this region; (ii) to assess soybean yields for different seasonal precipitation forecasts; and (iii) to assess differences in yields obtained with combinations of management practices (sowing dates and maturity groups) for different seasonal climate forecasts. 


\section{Materials and methods}

\subsection{IRI seasonal climate forecast}

IRI began issuing global seasonal climate forecasts in October 1997, using a two-tiered dynamically based multimodel prediction system (Mason et al., 1999). These forecasts are probabilistic and consider the expected occurrence of three climatologically equiprobable categories of seasonal total precipitation-below-, near-, and above-normal as defined by a 30-year base period in use at the time. Limits for the three categories are defined by ranking the latest 30 years of cumulative precipitation data for each trimester. The rank is divided into three terciles, the upper tercile defines the above-normal category, the lowest tercile defines the below-normal category, and the central tercile represents the normal category (thresholds for each weather station and each trimester are shown in Supplementary Table S1). Thus, the definition of the "normal" category in these forecasts does not imply that rainfall typically falls (or is more expected to fall) into that category. In fact, due to the used definition, rainfall has equal probability of falling into any of the three categories. The category defined here as "normal" only refers to the values that fall within the limits of the central tercile of the entire distribution. In order for any category to be published as being different from $33 \%$ (i.e., the climatological value), the probability of that category must be higher than or equal to $40 \%$ (https://iri.columbia.edu/ our-expertise/climate/forecasts/seasonal-climate-forecasts/). When not enough signal is captured in the forecasts to shift the probability of any of the categories, the forecast is defined as "climatology", meaning that there is equal chance for precipitation being in any of the three categories defined based on the observed climatology for the site. Therefore, while climatology refers to a scenario were none of the three categories have enough high probability of occurrence (less than 40\%), "normal" category means higher probability of precipitation occurrence within the central tercile. From October 1997 until June 2001, the forecasts were issued quarterly for the two upcoming consecutive 3-month periods, after which, they were issued monthly for the same two lead times, but additionally for two intermediate overlapping 3-month periods. IRI seasonal precipitation forecasts (IRI PRECIP from now on) have been issued approximately one-half month prior to the beginning of the first 3-month forecast period. The lead time is defined as the time between issuance and the start of the targeted period; starting in June of 2001, forecasts have been issued at 0.5-, 1.5-, 2.5-, and 3.5-month lead times. The IRI PRECIP forecasts are based on a re-calibration of model output from the U.S. National Oceanographic and Atmospheric Administration (NOAA)'s North American Multi-Model Ensemble Project (NMME). This includes the ensemble of seasonal prediction systems of NOAA's National Centers for Environmental Prediction, Environment, and Climate Change Canada, NOAA/Geophysical Fluid Dynamics Laboratory, NASA, NCAR, and COLA/University of Miami. The output from each NMME model is re-calibrated prior to creating a multi-model ensemble to produce objective probabilistic forecasts. The forecasts are presented on a 1-degree latitude-longitude grid. Previous evaluations of the performance of IRI's seasonal forecasts have found to be skillful for the seasons and regions known to have intrinsic predictability such as South American Pampas (Barnston et al., 2010; Goddard et al., 2003).

In the present study, we defined December-January-February (DJF) as the target trimester, since it includes the critical period for soybean seed number setting in the studied region (Fig. 1) (Andrade et al., 2015; Caviglia et al., 2004; Kantolic and Slafer, 2001).We consider the forecasts released in August (3.5-month lead), September (2.5-month lead), October (1.5-month lead), and November (0.5-month lead), to be used as a tool for defining agronomic management practices such as sowing date and maturity group (MG) of the cultivar to be sown.

\subsection{Sites, climate, and soil data}

Harvested soybean area in Uruguay averaged $c a$. 1.1 Mha during 2010-2016 and its spatial distribution was highly concentrated in the west of the country, where most agricultural suitable lands are located (Fig. 2). Weather stations used in this study were selected following the protocols defined by Grassini et al. (2015) and van Bussel et al. (2015), and the process described by Rizzo et al. (2021). Given the concentration of crop production in Uruguay, five weather stations were enough to cover $71 \%$ of the national soybean area.

Long-term weather data source selection and quality control were done based on the Global Yield Gap Atlas protocol (Grassini et al., 2015). Daily maximum and minimum air temperature, precipitation, and relative humidity were derived from EEMAC (Mario A. Cassinoni Experimental Station from Faculty of Agronomy, for the weather station in Paysandú), INIA (National Institute of Agricultural Research, for weather stations in La Estanzuela and Treinta y Tres), and INUMET (Uruguayan Meteorological Institute, for weather stations in Mercedes and Trinidad) weather stations (Fig. 2). Observed daily incident solar radiation was not available for the INUMET and INIA weather stations, hence data from NASA-POWER (https://power.larc.nasa.gov) were used as the source of daily incident solar radiation for all sites. Previous works evaluating the NASA-POWER solar radiation data have reported a very good agreement with measured solar radiation data in international (van Wart et al., 2013; White et al., 2011), regional (Aramburu Merlos et al., 2015), and local studies (Ernst et al., 2016). We combined data from EEMAC, INIA, INUMET, and NASA-POWER for each weather station to build a complete database of daily temperature, precipitation, and solar radiation records for 2000-2016.

Predominant soil types cultivated with soybean in each region used in our study were identified based on data provided by Natural Resources Directory of Uruguayan Ministry of Livestock, Agriculture and Fisheries (www.mgap.gub.uy/unidad-organizativa/direccion-generalde-recursos-naturales). To account for the soil variability the procedure already described in Rizzo et al. (2021) was used. In summary, we selected a group of soil types needed that cover $90 \%$ of the soybean harvested area in the zone of influence of each weather station (10 to 14 soils series) based on the CONEAT map (i.e. most detailed national-level soil feasibility map; $1: 40,000$ ). Soil hydrological constants required to run crop simulation models (i.e, field capacity and permanent wilting point) were estimated based on calculations using soil properties following Ritchie and Crum (1989), after the revisions made by Gijsman et al. (2002). Maximum rooting depth was allowed to reach the maximum soil depth of each soil, ranging from 0.8 to $1.3 \mathrm{~m}$.

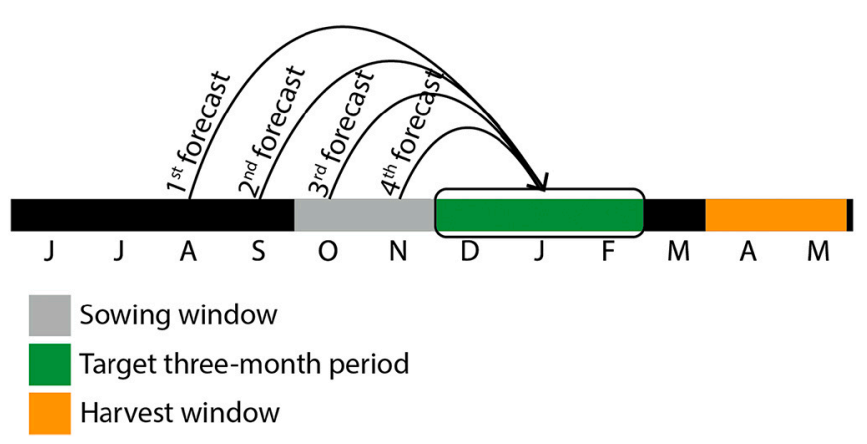

Fig. 1. Representation of the decision-making process for single soybean. The target period of interest (critical period, i.e. December-January-February) is shown in green, the sowing window is shown in gray and the harvest window ( $i$. $e$, the period in which most of the soybean crops are harvested in Uruguay) is shown in orange. The forecasts are released monthly and we considered four lead periods for the target trimester: August -the first forecast with a 3.5-month lead time, to November -the fourth forecast with a 0.5-month lead time. (For interpretation of the references to colour in this figure legend, the reader is referred to the web version of this article.) 


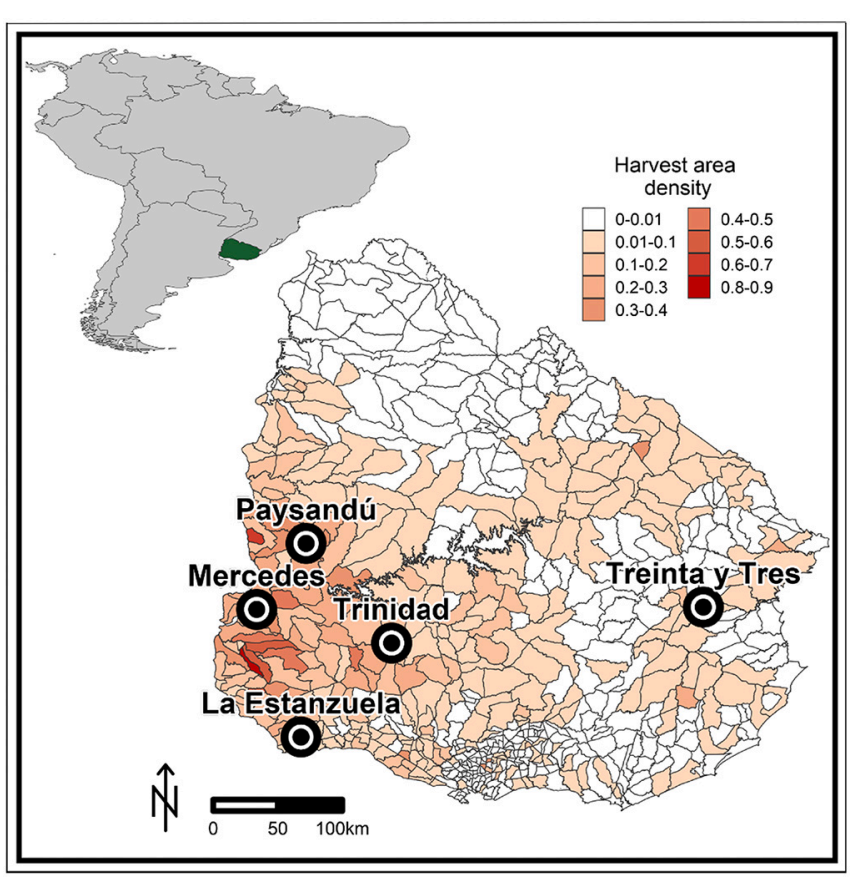

Fig. 2. Location of the weather stations (black dots) and soybean harvested area density per enumeration-area (as proportion of the total area of each enumeration-area), from the 2011 agricultural census (DIEA, 2011). Inset shows the location of Uruguay within the conterminous South America.

\subsection{Simulated water-limited yield, $M G$, and sowing dates}

Water-limited yield ( $\mathrm{Yw}$ ) is defined as the yield of a cultivar when grown in an environment to which it is adapted; with non-limiting nutrients; with pests, weeds, and diseases effectively controlled; but with crop growth limited by water supply (i.e., rainfed) and its distribution during the growing season (Van Ittersum et al., 2013). Yw was estimated through simulations using CROPGRO-Soybean model embedded in DSSAT v4.6 (Hoogenboom et al., 2015; Jones et al., 2003). Genetic coefficients were derived from Aramburu Merlos et al. (2015) where the model showed satisfactory performance to simulate Yw. We used CROPGRO-Soybean model because it is a well validated model under the conditions of the target area of this paper. Furthermore, DSSAT has been widely used in similar studies because of its ability to integrate effects of climate, soil, management practices, genetics, and their interactions (Bert et al., 2007; Fraisse et al., 2008; de Nóia Júnior et al., 2020). To account for the differential water availability of each soil at sowing date of each crop through the studied period, the entire crop sequence was simulated, and we assumed $50 \%$ of plant-available soil water in the first year of the time series.

To account for the diversity on cropping systems that are usually implemented in Uruguay, the dominant crop rotations at each of the five locations used in this study were retrieved from the cropping sequences reported in the Planes de Uso de Suelos (soil use plans, information provided by Dirección General de Recursos Naturales del Ministerio de Ganadería Agricultura y Pesca, www.mgap.gub.uy/unidad-organizativa/dire ccion-general-de-recursos-naturales). For each location we simulated single (S1) and double-cropped soybean cropping systems (S2; i.e., soybean sown immediately after harvest of a winter cereal crop, hence two cash crops per year). To this aim, the main representative cropping sequences were simulated: (i) one-year sequence: cover crop/S1 (i.e. continuous soybean), (ii) two-year sequence: cover crop/S1-wheat/S2, and (iii) three-year sequence: cover crop/S1-wheat/double-cropped maize-fallow/S1 (this sequence was not simulated in Treinta y Tres). For each cropping sequence in each location, S1 Yw were simulated for all combinations of 11 sowing dates (first sowing date on September 1st, and last on January 29th, with an interval of 15 days between subsequent sowing dates) and three MGs (IV, V and VI). Similarly, for S2 we simulated Yw for all combinations of 11 sowing dates (from December 1st to February 9th, with an interval of 7 days between subsequent sowing dates) and three MGs (IV, V, and VI). Harvesting was set to be performed once the crop reached physiological maturity as simulated by the crop model.

For some locations the earliest soybean sowing dates considered in this study (September) imply a high risk of frost damage (i.e., more than $50 \%$ chance of a mild frost for 15 September), poor emergence, and delayed initial crop development. While most farmers would start sowing maize in early September, early soybean sowing dates are not recommended before the first week of October. The aim to simulate very early sowing dates was to explore a wide range of sowing date $\times$ MG combinations. However, we recognize that model may overpredict yield and crop growth under such conditions due to misrepresentation of the involved stresses and processes (Schoving et al., 2020).

\subsection{Definition of best management strategies}

Three management strategies were assessed at each studied location through Uruguay: (i) dominant (DOM; i.e. the combination of sowing date and MG most frequently used by farmers); (ii) best for belownormal seasonal precipitation (BB; i.e. the best combination of sowing date and MG to allow maximum yield and lowest risk under belownormal precipitation); and (iii) best for above-normal seasonal precipitation (BA; i.e. the best combination of sowing date and MG to allow maximum yield and lowest risk under above-normal precipitation).

To define DOM scenario, the most commonly used management practices were retrieved from 2009 to 2016 agronomic records from farmers of the Uruguayan Federation of Regional Consortia of Agricultural Experimentation (FUCREA, using its Spanish acronym, www. fucrea.org). Retrieved information included: average sowing dates, dominant cultivar, and maturity group; and the information was subsequently validated by national experts. Plant population density across all locations and scenarios was set to 35 plant $\mathrm{m}^{-2}$, a population that maximizes yield in a wide range of environments and MGs under local conditions (Gaso, 2018). The dominant MG used across all locations and for both, single and doubled-cropped soybean was MG VI. Single soybean sowing dates varied from November 10th to November 19th, and for double-cropped soybean, it ranged from December 2nd to December 24th. Detailed dominant management practices for each region are shown in Table 1.

BB and BA were defined for each location independently, based on 14 years of simulated crop yields for the combinations of 11 sowing dates and three MGs, as defined in the previous section. The simulations were then classified as belonging to below- or above-normal year, based on the accumulated precipitation of the target three-month period. The simulation was classified as below-normal if the accumulated precipitation in the target three-month period was lower than the lower-bound for the central tercile used by IRI for each grid point (Supplementary Table S1), and as above-normal if the accumulated precipitation was higher than the upper-bound of the central tercile. Finally, soybean seed yields for below- and above-normal simulations were assessed for each location. The combination of sowing date and MG resulting in the highest average seed yield and the highest $25 \%$ percentile (defined as "lowest risk"), was selected as the best set of management practices of each scenario (i.e., $\mathrm{BB}$ or $\mathrm{BA}$ ).

\subsection{Data analysis}

The methodological framework followed in this study is described in Fig. 3. First, we evaluated the interannual and intra annual skill of the IRI PRECIP forecasts across the Uruguay main crop producing area. The interannual skill evaluation consisted of a hit score (Heidke), i.e., the measure of the proportion of years when categories were successfully 
Table 1

Dominant (DOM) and best set of sowing date (SD) and maturity group (MG) for Below and Above normal forecasted precipitations for each soybean cropping system (single, S1; and double-cropped soybean, S2) for each weather station, based on the highest average seed yield and/or highest 25th percentile among the total simulated combinations. Dominant SD and MG were retrieved from a previously published study on soybean yield gaps in Uruguay (Rizzo et al., 2021).

\begin{tabular}{|c|c|c|c|c|c|c|c|}
\hline \multirow{2}{*}{$\begin{array}{l}\text { Weather } \\
\text { station }\end{array}$} & \multirow[t]{2}{*}{ CS } & \multicolumn{2}{|l|}{ BB } & \multicolumn{2}{|l|}{ BA } & \multicolumn{2}{|l|}{ DOM } \\
\hline & & SD & MG & SD & MG & SD & MG \\
\hline \multirow[t]{4}{*}{ La Estanzuela } & S1 & 15 & IV & $1 \mathrm{Sep}^{\mathrm{a}}$ & IV & 10 & VI \\
\hline & & Dec & & & & Nov & \\
\hline & S2 & 15 & IV & 12 Jan & IV V VI & 15 Dec & VI \\
\hline & & Dec & & & & & \\
\hline \multirow[t]{3}{*}{ Mercedes } & S1 & 15 & IV & $1 \mathrm{Oct}$ & IV & 10 & VI \\
\hline & & Dec & & & & Nov & \\
\hline & S2 & 12 Jan & IV V VI & $1 \mathrm{Dec}$ & IV V VI & 15 Dec & VI \\
\hline \multirow[t]{4}{*}{ Paysandú } & S1 & 30 & IV & $1 \mathrm{Sep}^{\mathrm{a}}$ & IV & 10 & VI \\
\hline & & Dec & & & & Nov & \\
\hline & S2 & 29 & IV & 12 Jan & IV V VI & $1 \mathrm{Dec}$ & VI \\
\hline & & Dec & & & & & \\
\hline \multirow{3}{*}{ Trinidad } & S1 & 15 & IV & 16 & IV & 10 & VI \\
\hline & & Dec & & $\operatorname{Sep}^{\mathrm{a}}$ & & Nov & \\
\hline & S2 & $5 \mathrm{Jan}$ & IV & 15 Dec & IV V VI & 15 Dec & VI \\
\hline \multirow[t]{3}{*}{ Treinta y Tres } & S1 & 14 Jan & IV & 16 & IV & 19 & VI \\
\hline & & & & $\operatorname{Sep}^{\mathrm{a}}$ & & Nov & \\
\hline & S2 & 12 Jan & IV V VI & 15 Dec & IV & $22 \mathrm{Dec}$ & VI \\
\hline
\end{tabular}

${ }^{a}$ Not recommended for agronomic purposes with current genotypes and management practices, see note in the discussion.

predicted (i.e., the forecasted precipitation category in a given threemonth period was consistent with the observed precipitation category for the same three-month period) over the total number of predictions. In the intra annual skill evaluation, the frequency of successfully forecasted categories was assessed for each of the 12 possible three-month period combinations across the year; and its four possible lead times.

In a second step, we assessed the impact of cropping system decisions and IRI PRECIP forecast evaluating the relationship of the successfully forecasted precipitation categories and the soybean yields. The difference between average soybean seed yield $\left(\mathrm{Mg} \mathrm{ha}^{-1}\right)$ for below- and above-normal forecasted categories for DJF three-month period (released between August and November), among all weather stations and simulated cropping systems were assessed by means of $t$-test analysis. The total number of observations into each forecasted category was classified based on failure or success of the precipitation forecast (as fail or hit, respectively), and mean seed yield difference between fail and hit category was evaluated by a $t$-test.

In a third step, this assessment allowed us to identify the best set of agronomic management practices (i.e., the combinations of sowing date and MG that allows to achieve the highest yield with lowest probability of low yields) was assessed for the different forecast scenarios. In the fourth step we contrasted the effect of three predefined set of sowing dates and MGs to the three most frequent scenarios of IRI PRECIP forecasts (below-, above-normal, and climatology). We investigated the effect on soybean seed yield by applying three different management strategies (DOM, BB, and $\mathrm{BA}$ ) under three possible forecasted precipitations scenarios: (i) below-normal; (ii) above-normal; and (iii) climatology (i.e. not enough signals to predict a normal, below- or above-normal precipitations). Results for each management strategy were summarized in boxplots, for the combinations of forecasted category and location, and the difference of yield between management strategy for each soybean cropping system under each forecasted scenario was evaluated by means of a $t$-test.

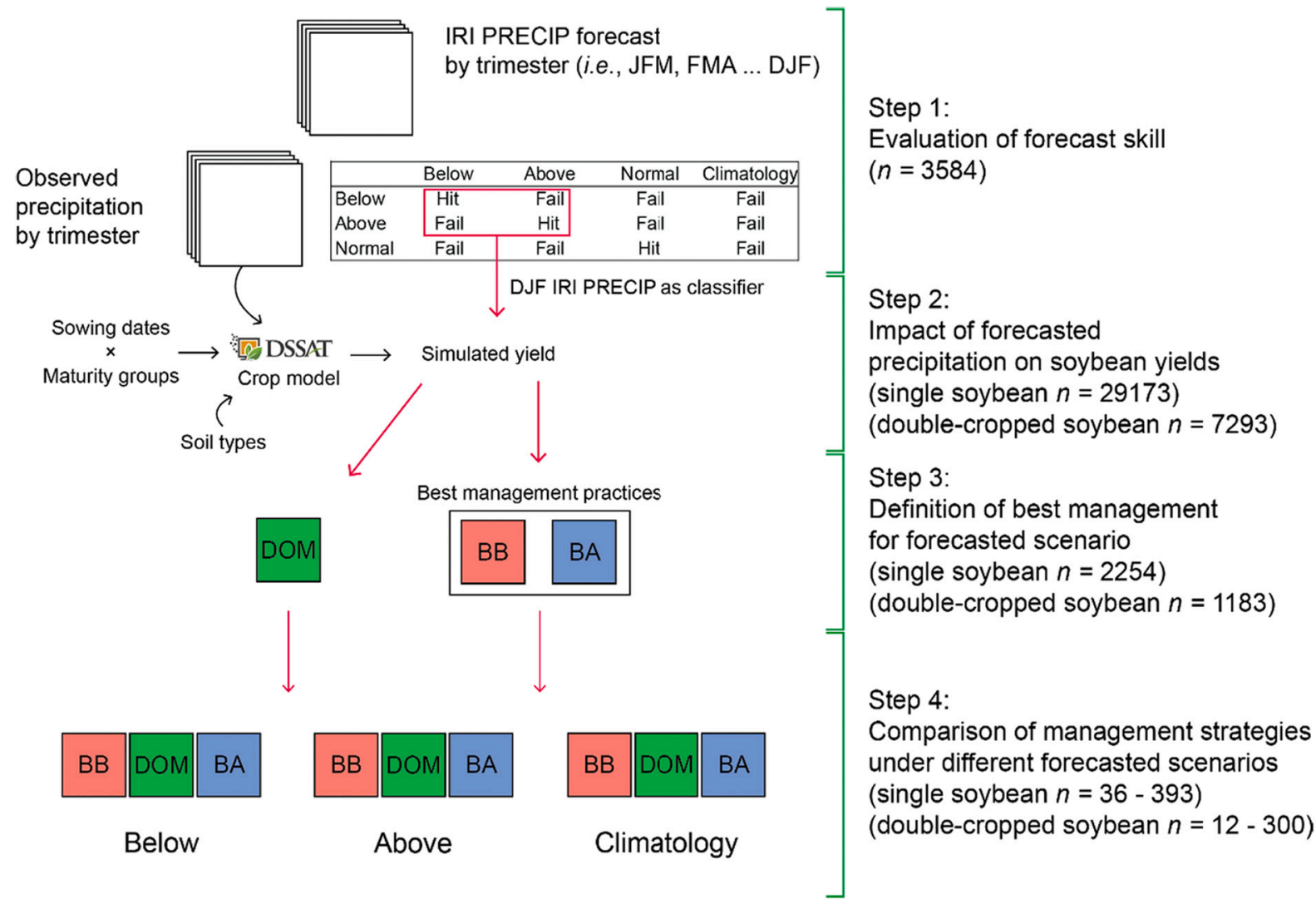

Fig. 3. Methodological framework followed in this study. 


\section{Results}

\subsection{IRI PRECIP forecast skill assessment}

There was a total of 620 released forecasts for Paysandú and 668 for La Estanzuela, Mercedes, Trinidad and Treinta y Tres from a total of up to 672 possible forecasts for each weather station in the studied period (4 lead periods $\times 12$ months $\times 14$ years). We identified a high skill of the IRI PRECIP forecast to predict categories of below- and above-normal precipitation scenarios through the main soybean cropping area in Uruguay (Fig. 4). The forecasts were able to successfully predict the below-normal category scenario between $71 \%$ for the weather station in Paysandú and $80 \%$ for weather stations in La Estanzuela and Mercedes, averaging a success of $77 \%$ hit score of total predictions that were realized for this scenario through all weather stations during the study period (2003-2016). The above-normal precipitation scenario presented a wider accuracy variation, ranging from 33\% for La Estanzuela to $86 \%$ for the weather station located in Paysandú, with an average of $60 \%$ across all weather stations (Fig. 4). "Normal" precipitation scenario (i.e., precipitation falling within the central tercile) was not accurately predicted by the seasonal forecast in any of the forecasts made for that scenario. Indeed, "normal" precipitation scenario had the lowest number of forecasts realized, ranging from 9 to 14. The results shown in Fig. 4 indicate that the number of forecasts for "Climatology" (equal chance of the three categories) varied between 434 for Paysandú to 489 for Treinta y Tres.

When the frequency of hits was disaggregated by trimester and lead periods for each forecasted precipitation scenario, IRI PRECIP forecasts showed higher frequency of hits for the below-normal precipitation scenario than normal or above-normal precipitation scenario (Fig. 5). Indeed, we found that normal precipitation scenario was never successfully forecasted for any weather station, and it is the least frequently forecasted scenario (Fig. 4). Below-normal precipitation scenario showed a consistent pattern of hits for all trimesters except for JFM and JAS. However, predictability of the above-normal precipitation scenario showed higher seasonality, with higher frequency of hit from the end of the austral winter (JAS) until the beginning to middle austral summer (DJF). Although similar seasonality was found across weather stations for the number of hits in the above-normal precipitation scenario, some variation among weather stations was detected. For example, Paysandú had 49 above-normal precipitation forecasts from JAS to DJF ( $89 \%$ of the total number of forecasts produced in the year) with an average proportion of success of $86 \%$. However, La Estanzuela showed a narrower period of successfully forecasted above-normal precipitation scenario (from SON to DJF) with 46 forecasts ( $80 \%$ of the total released forecasts across the year) with an average proportion of success of $31 \%$.

\subsection{Impact of cropping-system and IRI PRECIP forecast on soybean seed yield}

We evaluated the performance of S1 and S2 using the DOM for those years when a below- or above-normal precipitation forecast was released for the DJF three-month period at any of the four lead times. The average $\mathrm{S} 1$ seed yield across all years with a below- or above-normal precipitation forecast was $3.1 \mathrm{Mg} \mathrm{ha}^{-1}$ (Fig. 6A). Similarly, the average S2 seed yield across all years with a below- and above-normal precipitation forecast was 2.8 and $2.9 \mathrm{Mg} \mathrm{ha}^{-1}$, respectively (Fig. 6B). These small differences in yield result from the use of the DOM management practice, which is uniform and indifferent to climate forecast scenarios, thus not taking advantage of above-normal years, nor mitigating losses in below-normal years. The results in the below- and above-normal precipitations categories in panels A and B were grouped by the years for which the observed precipitation category was successfully or unsuccessfully forecasted by the IRI PRECIP forecast in panels C and D, respectively. The average S1 seed yield when below-normal precipitation scenario was successfully forecasted was $2.6 \mathrm{Mg} \mathrm{ha}^{-1}$, while when this scenario was unsuccessfully forecasted (normal or above-normal precipitations were observed) the average seed yield was $4.2 \mathrm{Mg} \mathrm{ha}^{-1}$ (Fig. 6C). When above-normal precipitation scenario was successfully forecasted the average S1 seed yield was $3.2 \mathrm{Mg} \mathrm{ha}^{-1}$, while when this scenario was unsuccessfully forecasted (normal or below-normal precipitations were observed) the average seed yield was $2.2 \mathrm{Mg} \mathrm{ha}^{-1}$. There was a significant difference $(p<0.01)$ in average seed yield between successfully $\left(2.4 \mathrm{Mg} \mathrm{ha}^{-1}\right)$ and unsuccessfully $\left(3.9 \mathrm{Mg} \mathrm{ha}^{-1}\right.$ ) forecasted below-normal precipitations for S2 (Fig. 6D). However, although the average $\mathrm{S} 2$ seed yield was higher when the above-normal
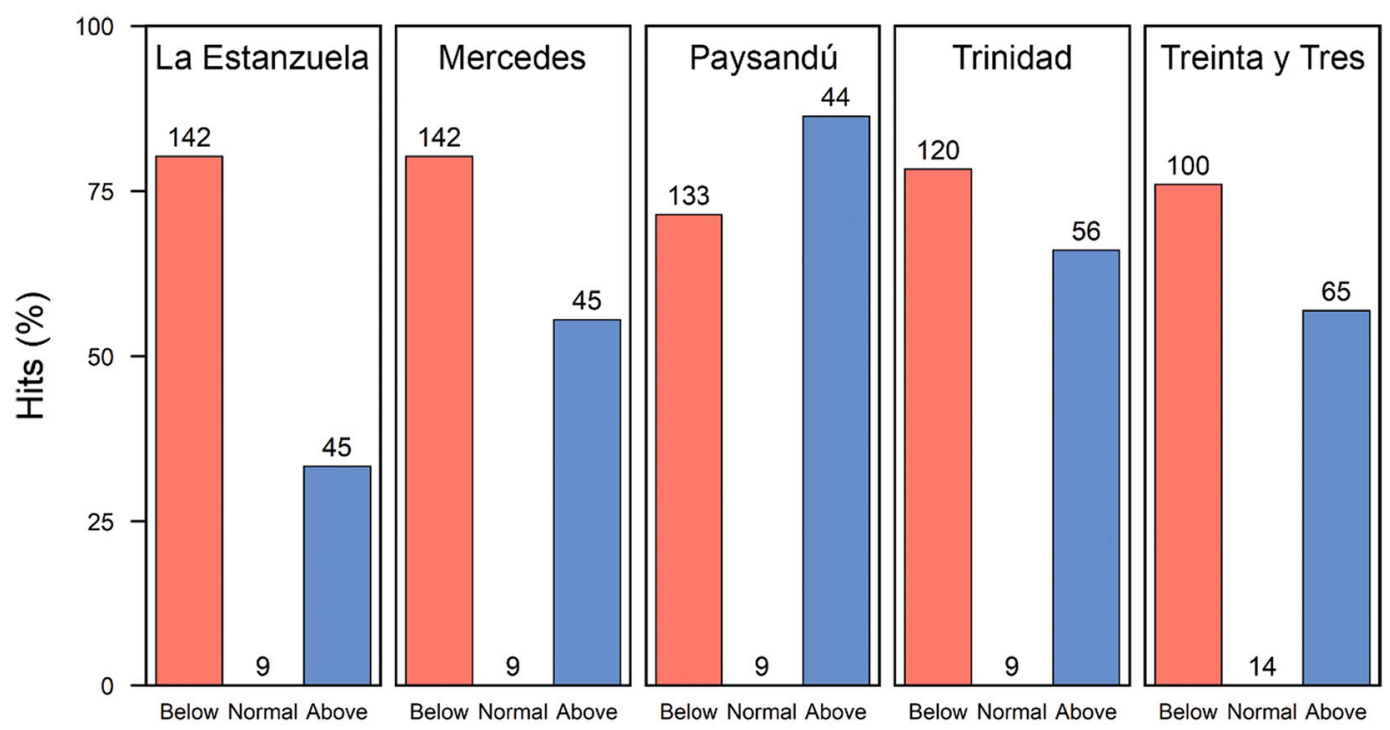

Forecasted category

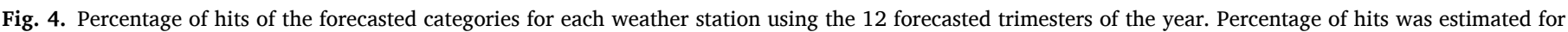

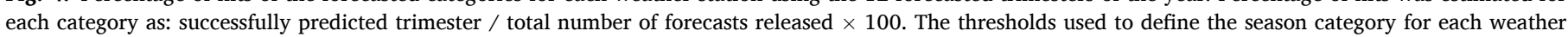

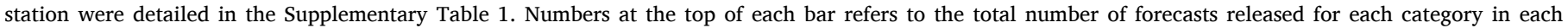
weather station. 

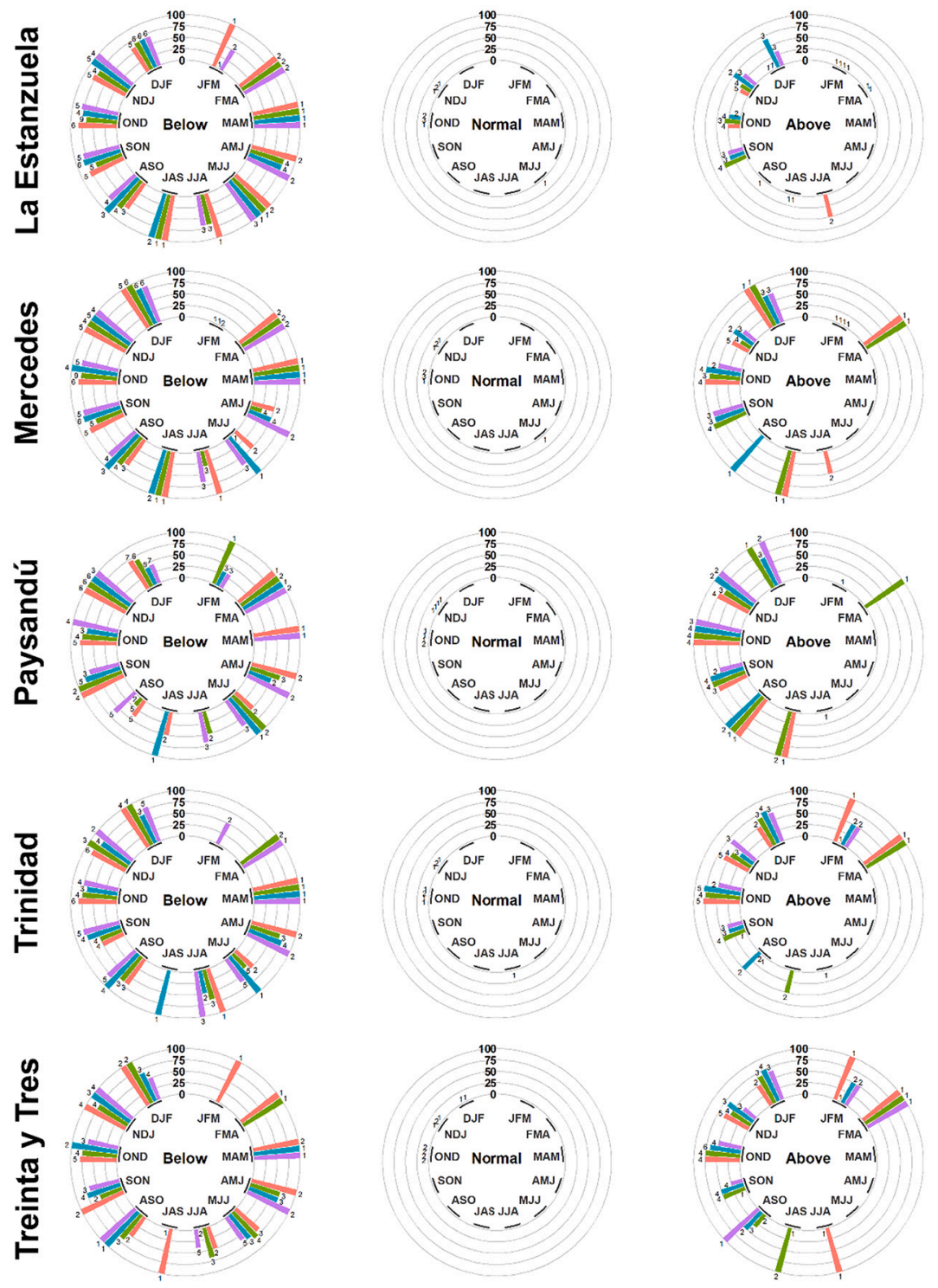

Forecast release lead times

3.5-month

\section{5-month}

Fig. 5. Hit percentage for all trimesters and forecast release lead times for each predicted category (estimated for each release lead times within each category as: successfully predicted trimester/total number of forecasts released $\times 100$ ). Numbers above each bar represent the total number of forecasts released for each forecast release lead times within trimester. Within each trimester the four forecast release lead times are shown (3.5-month lead time, orange; 2.5 -month lead time, green; 1.5-month lead time, blue; and 0.5-month lead time, violet). (For interpretation of the references to colour in this figure legend, the reader is referred to the web version of this article.) precipitations was successfully forecasted ( 2.9 versus $2.5 \mathrm{Mg} \mathrm{ha}^{-1}$ ), the difference was non-significant.

\subsection{Best sowing date and MG decisions based on IRI PRECIP forecasts}

The simulated yield for the above and below-normal occurred rainfall at the different locations varied depending on MGs and sowing dates (Figs. 7 and 8). In La Estanzuela, we found yield penalties for sowing dates later than Dec 30th for all MG under below or above forecasted rainfall scenarios. Also in this region, sowing dates earlier than Nov 30th show yield penalties under below-normal rainfall (Fig. 7). In Paysandú, earlier sowing dates (before Oct 31st) showed the highest Yw under above-normal rainfall conditions, with highest benefits for MG IV. However, for the below-normal rainfall we found that delayed sowing dates ( 75 days later than the optimal for above-normal rainfall) resulted in the highest Yw (Fig. 8). Similar effects of sowing dates and MG on the Yw were observed in Mercedes, Trinidad and Treinta y Tres (Supplementary Fig. S1-3). Best combinations of sowing dates and MG for each soybean cropping systems for below- and above-normal precipitation forecasts (i.e. $\mathrm{BB}$ and $\mathrm{BA}$ ) were determined as the ones obtaining highest average seed yield and/or highest 25th percentile among the total simulated combinations (Table 1 ).

\subsection{Dominant management versus optimal management decisions based on IRI PRECIP forecast}

The successful use of a forecast implies in practice the capacity to adapt the management practices to the possible future weather conditions. Fig. 9 shows the Yw for the dominant farmer management practices (DOM), compared to optimal management strategies (BB and BA) under below-normal (Below), above-normal (Above) and Climatology forecast scenarios. When a below-normal precipitation scenario was forecasted, the adoption of a BB management strategy for S1 resulted in higher seed yields ( $3.7 \mathrm{Mg} \mathrm{ha}^{-1} ; p \leq 0.01$ ), compared to the DOM (3.1 $\mathrm{Mg} \mathrm{ha}^{-1}$ ) and $\mathrm{BA}\left(1.7 \mathrm{Mg} \mathrm{ha}^{-1}\right)$ strategy under this forecasted scenario for all locations (Fig. 9). The adoption of the BA instead of the BB management strategy when there was a below-normal precipitation forecasted scenario resulted in large penalties in seed yield $(2.0 \mathrm{Mg}$ 


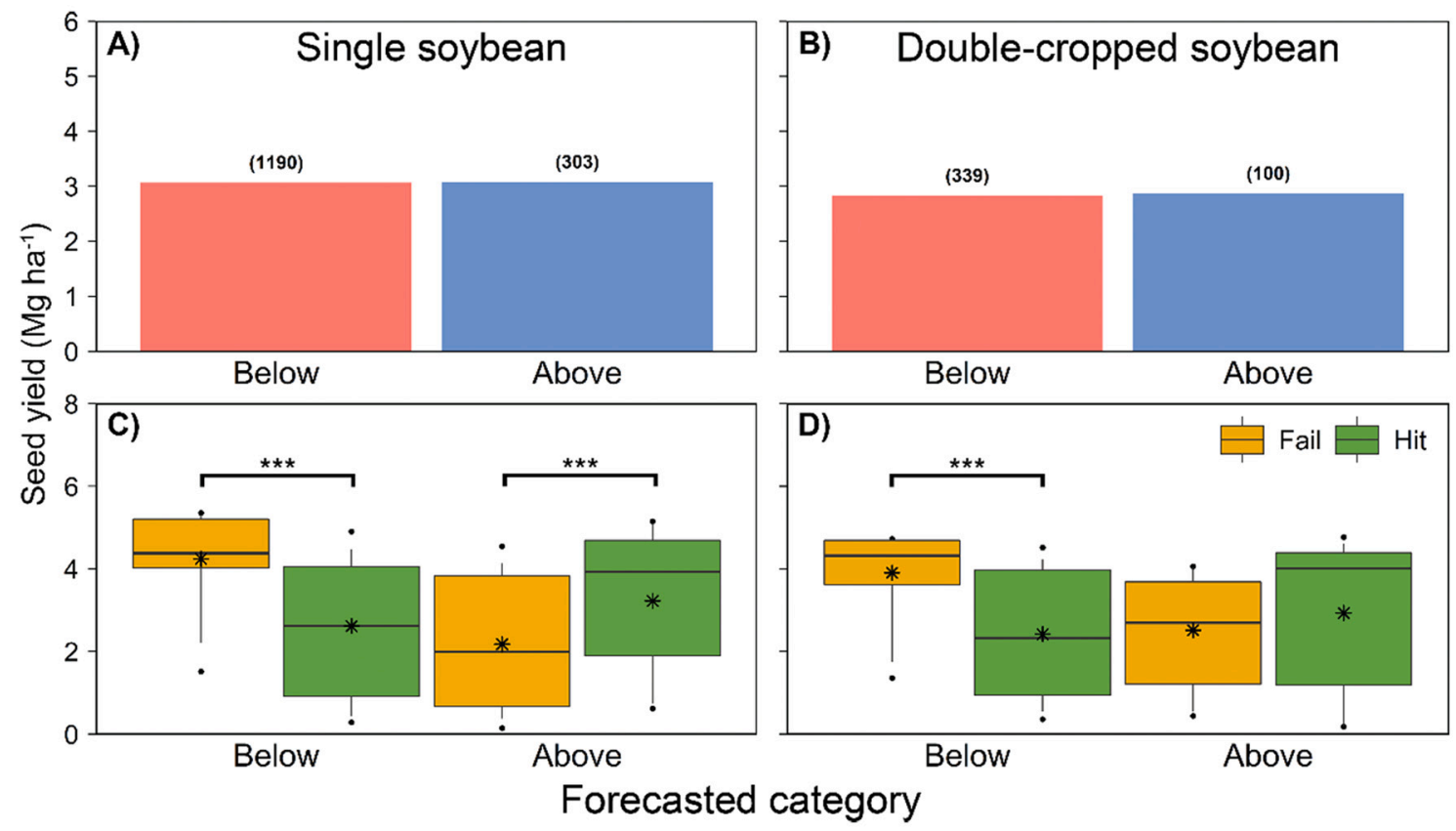

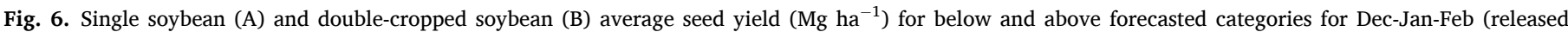

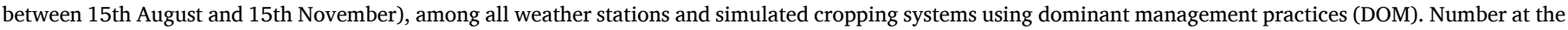

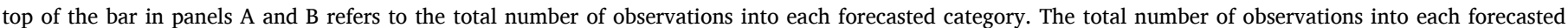

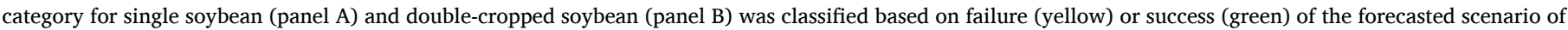

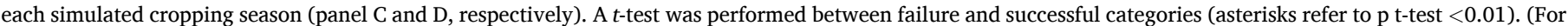
interpretation of the references to colour in this figure legend, the reader is referred to the web version of this article.)

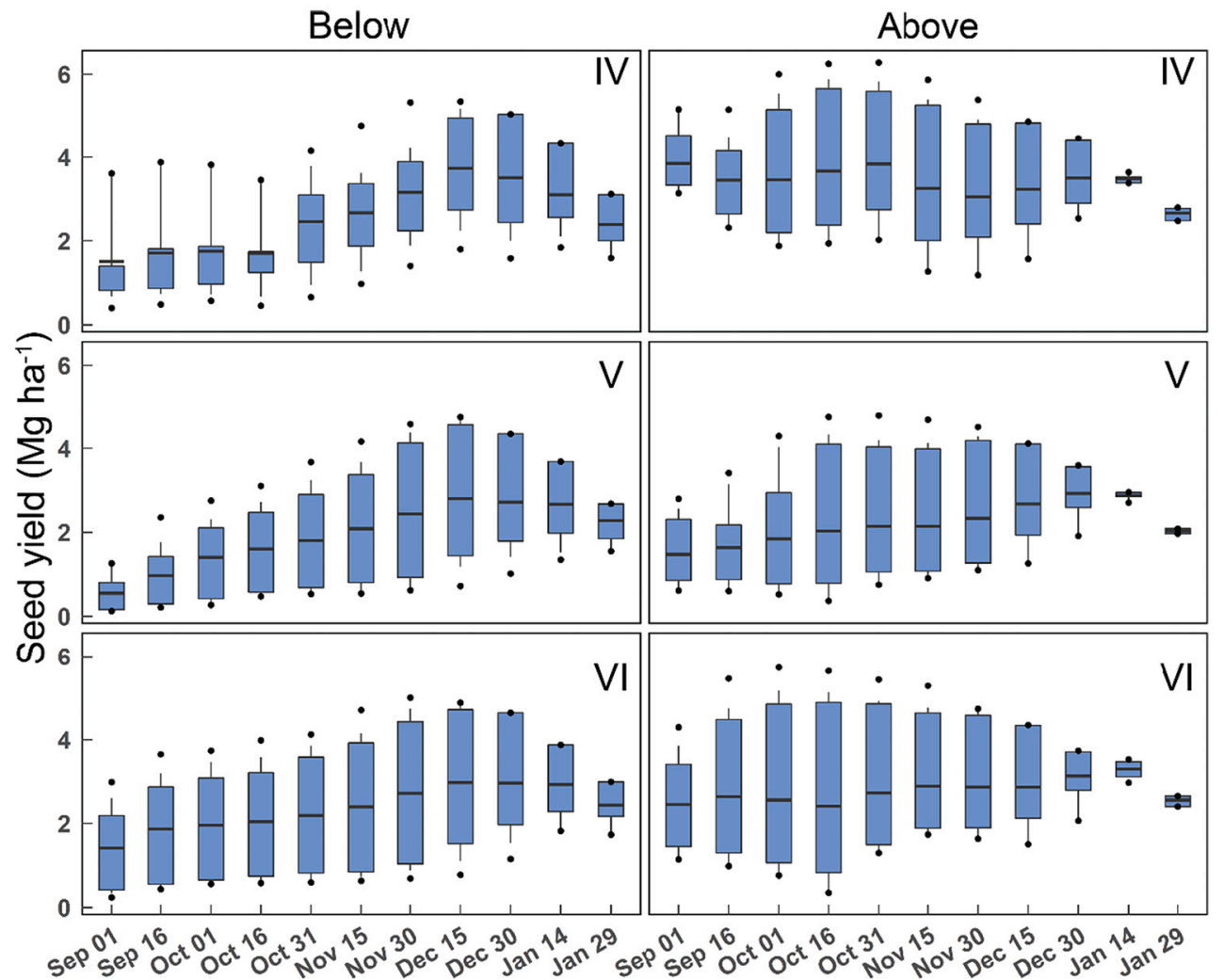

Sowing date
Fig. 7. Single soybean yield $\left(\mathrm{Mg} \mathrm{ha}^{-1}\right)$ as a function of sowing date and maturity groups (IV, $\mathrm{V}$ and VI, as noted at the top right corner of each panel) for above and below forecasted categories (left and right panel, respectively) at La Estanzuela. Boxes delimit first and third quartiles. Solid line inside the box indicates the mean. The upper and lower end of the vertical lines represent the 10 and $90 \%$ percentile. The upper and lower points represent the 5 and $95 \%$ percentile. The number of observations into each boxplot ranged from 48 to 240 . 


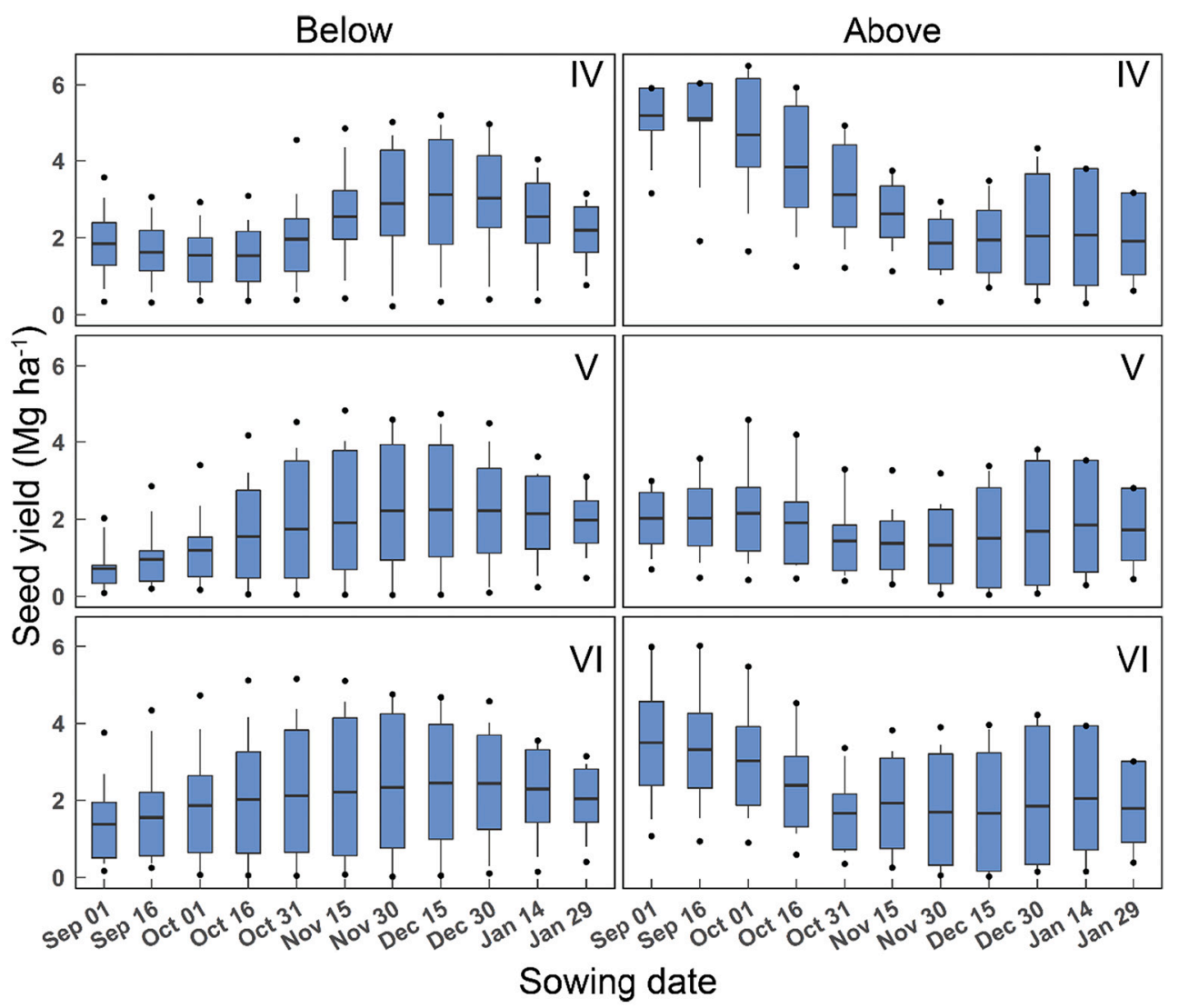

Fig. 8. Single soybean yield $\left(\mathrm{Mg} \mathrm{ha}^{-1}\right)$ as a function of sowing date and three maturity groups (IV, V and VI, as defined at the top right corner of each panel) for above and below forecasted categories (left and right panel, respectively) at Paysandú. Boxes delimit first and third quartiles. Solid line inside the box indicates the mean. The upper and lower end of the vertical lines represent the 10 and $90 \%$ percentile. The upper and lower points represent the 5 and $95 \%$ percentile. The number of observations into each boxplot ranged from 80 to 224 . $\mathrm{ha}^{-1}$ ). When an above-normal precipitation scenario was forecasted, the BA management strategy showed a significantly higher seed yield (4.7 $\left.\mathrm{Mg} \mathrm{ha}^{-1} ; p \leq 0.01\right)$ through all studied locations, than DOM (3.1 Mg $\left.\mathrm{ha}^{-1}\right)$ and $\mathrm{BB}\left(3.1 \mathrm{Mg} \mathrm{ha}^{-1}\right)$. Interestingly, for S1 cropping system the adoption of $\mathrm{BB}$ management strategy under an above-normal precipitation forecast, resulted in lower yield penalties $\left(1.6 \mathrm{Mg} \mathrm{ha}^{-1}\right)$ than BA under a below-normal precipitation forecast $\left(2.0 \mathrm{Mg} \mathrm{ha}^{-1}\right)$. It can be inferred from these results that while it is possible to determine optimal management strategies (BB, BA) for the different forecast scenarios (Above, Below, Climatology), the adoption of these strategies for a riskaverse farmer, will depend mainly on the reliability of the forecast.

For those years with a climatology forecast (i.e., none of the climatological categories had a probably higher than 40\%), for S1 cropping system the BB strategy resulted on average the management practice that allowed the highest and most stable seed yields $\left(3.9 \mathrm{Mg} \mathrm{ha}^{-1}, \mathrm{CV}=\right.$ $30 \%)$. For S1, the penalty for applying the DOM management instead of adopting the BA strategy under above-normal precipitation forecasts is higher than the penalty for adopting the DOM strategy instead of BB for years with below-normal precipitation forecasts (1.6 and $0.7 \mathrm{Mg} \mathrm{ha}^{-1}$, respectively). A clearly different behavior was identified for S2, where no significant differences were found between the different management strategies under any of the three forecasting scenarios through all studied locations.

\section{Discussion}

The influence of ENSO has been previously reported for main crop producing areas (Ropelewski and Halpert, 1987). Previous studies in South America have assessed the impact of the different ENSO phases on crop yields (Aramburu Merlos et al., 2015; Fraisse et al., 2008; de Nóia Júnior et al., 2020; de Nóia Júnior and Sentelhas, 2019). These previous reports have used a classification of each observed crop season to make an ex-post evaluation of the effect of each ENSO phase on the crop yields.
In the present study, we used a routinely available seasonal precipitation forecast to access the potential usefulness of these forecasts as a tool to support farmers management decision making well before the beginning of each cropping season. To that aim, we developed an approach to firstly evaluate the skill of the seasonal precipitation forecast on its ability to predict the seasonal precipitations, and to secondly evaluate the impact of making informed management decisions based on the released forecast. To our knowledge, this is the first study evaluating the application of a routinely available precipitation forecast to guide farmers management decisions. As a result, our work provides new insights to guide decisions that can significantly improve average yields by capitalizing favorable years and improving defensive management in unfavorable ones. We found that the IRI PRECIP forecasts have high skill for anticipating the below- and above-normal precipitation scenarios for the seasons that include the most relevant phase for soybean production in Uruguay. These results are consistent with previous skill evaluations of the IRI PRECIP forecast for this region (Barnston et al., 2003; Goddard et al., 2003).

While recognizing that farmer decision making is complex and influenced by several factors, skillful forecasts for below- and abovenormal precipitation scenarios can support management decisions, allowing to decide if a field should be sown or not, which crop to sow in each field and to select the most efficient set of management practices for a given field. One complication in using climate forecasts to inform decisions is that climate forecasts are probabilistic and farmer decisions are often deterministic. I.e., on the one hand a probabilistic forecast never fails even when the least probable forecasted scenario is the one that occurs (e.g., a forecast calls for only $15 \%$ chance of above-normal rainfall and the observed precipitation falls within the high tercile). Due to the probabilistic nature of climate forecasts, even the least likely scenario has a given chance of occurring and therefore, a probabilistic forecast is never "wrong". However, farmers must often consider this probabilistic information to make decisions that are deterministic (sow 


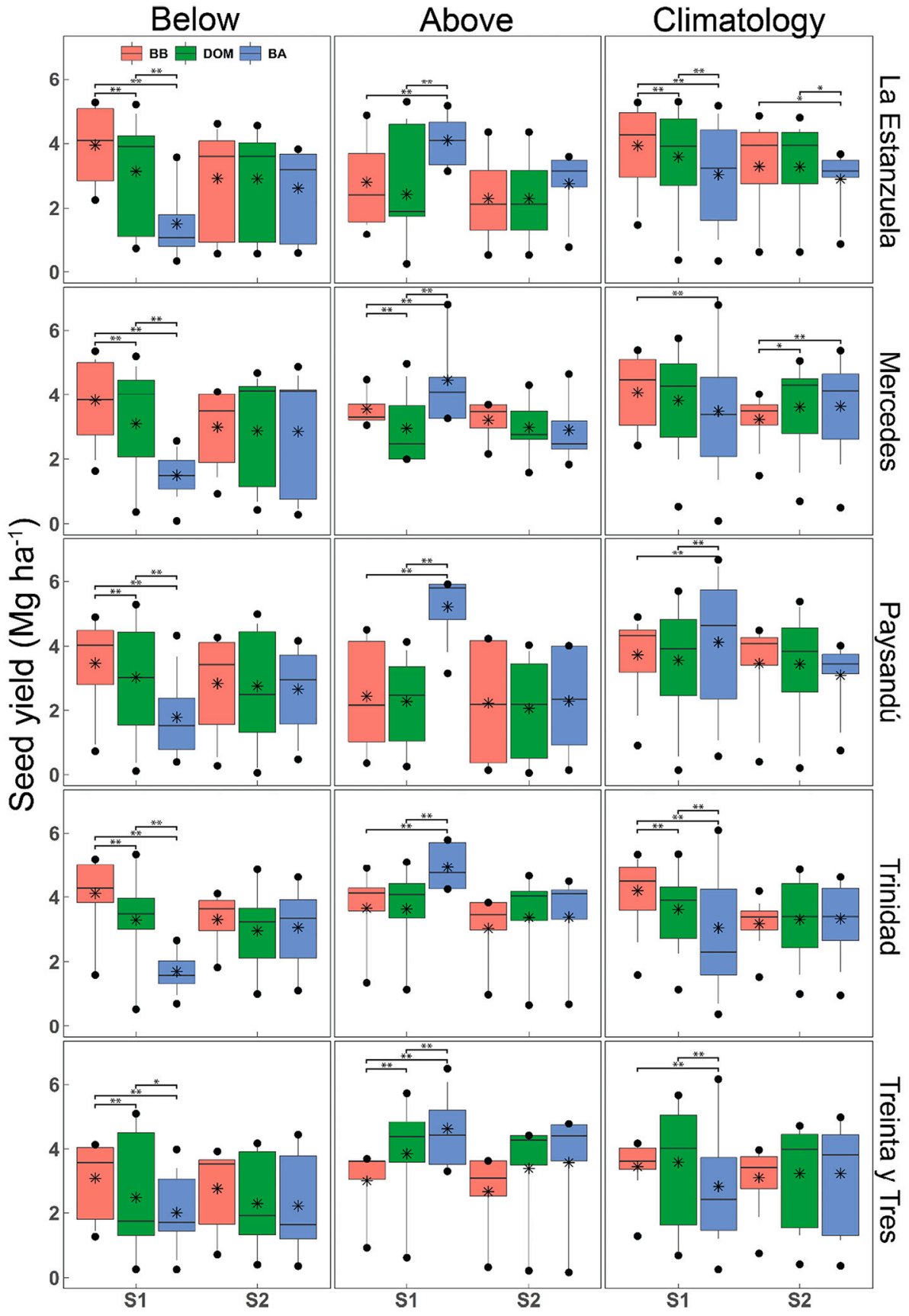

Fig. 9. Comparison of the effect of three management practices (dominant management, DOM; best management for below forecasted category, BB; and best management for above forecasted category, BA) on single (S1) and double-cropped (S2) soybean seed yield $\left(\mathrm{Mg} \mathrm{ha}^{-1}\right)$ as function of the IRI PRECIP forecast for five locations in Uruguay. Boxes delimit first and third quartiles. Solid line and star inside the box indicate median and mean, respectively. The upper and lower end of the vertical lines represent the 10 and $90 \%$ percentile. The upper and lower points represent the 5 and $95 \%$ percentile. The number of observations into each boxplot for S1 ranged from 36 to 393 , while for S2 it ranged from 12 to 300 . Asterisks above the braces refer to the $t$-test significance levels as follows: * $p \leq 0.05 ; * * p \leq 0.01$. early or late, use a given MG, etc.). In those cases, a forecast that is "categorical", i.e., is expressed as the chance of occurrence of a given category ("above-normal" or "below-normal"), can be more easily integrated in the complex process of decision-making. In other situations where farmers can shift the proportion of activities (e.g., percent of area sown to maize/soybeans/sorghum) the full distribution of a climate forecast can be considered (as opposed to consider only three categories) to inform decisions. The current paper focuses in the first type of decisions where farmers consider a probabilistic forecast to make deterministic decisions. Future work will focus on cases where farmers can consider the entire forecast distribution to inform non-deterministic decisions. In those cases, the skill of the climate forecasts may be better assessed using Bayesian methods instead of the hit scores used in the current article.

Our results are consistent with previous studies based on field trials which suggest the use of short-season soybean cultivars (i.e., MGs $=\mathrm{V}$ or shorter) and early sowing dates (November or earlier) under high precipitation scenarios (Gaso, 2018; Zanon et al., 2016). Under favorable years with above-normal rainfall, best sowing dates (BA) are in the early portion of the evaluated range of sowing dates, allowing the crop to fully exploit the growing season and capture higher amounts of incident solar radiation (Andrade et al., 2015; Rattalino Edreira et al., 2020; Zanon et al., 2016). In contrast, we found the best sowing dates for belownormal precipitation forecasts to be delayed towards the end of the evaluated sowing date range, avoiding that the soybean critical period (R3-R5) fall in DJF -that have a higher evaporative demand, and positioning it later in the season (Calviño and Monzon, 2009; Montoya et al., 2017). Similar escape strategies have been suggested for maize and sorghum in the region (Carcedo and Gambin, 2019). Results and conclusions do not change by allowing September sowing dates, because when these dates are selected as BA, the criteria select the "earliest possible" date (i.e., if restricted to October, it would select October 
instead of any other date).

Although we found that sowing dates should be as early as possible for seasons with above-normal forecasted precipitations, the risk of frost damage and poor emergence must be considered. In practice, there is a risk balance tradeoff between early sowing dates that expose the crop to cold temperatures at emergence but maximize yield, and later sowing dates that expose the crop to mild temperatures but penalizes yield due to drought stress. This also implies that there is an opportunity to improve management practices and breed for chill tolerance (e.g., Dong et al., 2021) allowing at the same time to sow early and escape water deficits by placing crop growth before the onset of water stress as it has been reported for similar latitudes in the northern hemisphere (Bowers, 1995). Indeed, previous studies have suggested the convenience of earlier sowing dates as a promising strategy to reduce risk under climate change leading to an extended cropping season (Olesen et al., 2011).

At the sequence level, a double-crop rotation (i.e. wheat-doublecropped soybean) have benefits compared to a single soybean due to the greater total productivity (Hansel et al., 2019) and environmental sustainability of the crop rotation (Andrade et al., 2015; Caviglia et al., 2019). In this study, we found a small penalty of double-cropped soybean $\left(0.25 \mathrm{Mg} \mathrm{ha}^{-1}\right)$ when no decision criteria were used (Section 3.2), which presumably would lead to increased adoption of double-cropped soybean, given its economic and environmental advantage. Interestingly, the advantage of making forecast-informed management decisions is reduced for double-cropped soybean. In fact, double-cropped soybean seems to be less affected by the forecast scenario and management decisions. Thus, for an informed farmer, being able to predict early in the year before sowing wheat (e.g., with a 3.5-month lead or more), the forecast scenario would allow the decision of growing a single soybean with BA management (when above normal is forecasted) or growing a double-cropped soybean after wheat (when below normal is forecasted). Similarly on a shorter timescale, a shorter lead time forecast would allow farmers to adapt management for soybean, given that the decision of growing a single or double-cropped soybean has been already made (Rizzo et al., 2021).

We found that the DOM management strategy adopted by farmers is focused on reducing yield penalties in drought scenarios. This risk adverse management allows farmers to minimize the yield losses under scenarios of below-normal precipitations, although it leads to higher yield losses under scenarios of above-normal precipitations. Similar results were found in a study based on a survey with farmers and technicians conducted by Bert et al. (2007), where farmers preferred conservative management in behavior that reduces losses in unfavorable years in detriment of obtaining possible gains in favorable years. Our work highlights the potential benefits of incorporating seasonal-specific management practices within the farmer decision making process, given that skillful seasonal precipitation forecasts such as IRI's are available. We recognize that by using a crop simulation model to evaluate the performance of soybean cropping systems under different forecasted precipitation scenarios implies that results are limited by model capability to represent the environmental factors and their interactions with management practices and genetics. Future work should incorporate field data to clearly define and validate the optimum set of management practices for each forecasted scenario, and to assess the actual impact on farmers' decisions to effectively capitalize potential gains.

The IRI PRECIP available leading times (i.e., 0.5-3.5 months) are long enough to provide meaningful insights about the expected precipitation during the critical period of rainfed soybean before its sowing date. Longer leading times would allow to inform decisions about the entire cropping sequence but currently available seasonal climate forecasts with longer lead times have low skill. On the other hand, shorter term seasonal forecast could be useful to support short term agronomic decision. For example, seasonal precipitation forecasts with lead times shorter than 0.5 month would support farmers to define fertilizer rates and its timing, plan field activities such as tillage timing, sowing and harvest dates, as well as biocide foliar application dates. Our results also suggest that IRI PRECIP can be helpful to accelerate the policy making process, allowing to release early warnings to farmers, as well as to provide insurance and/or subsidies to alleviate negative effect of unfavorable climate scenarios. Because of the potential usefulness of seasonal precipitation forecast shown here, we emphasize the need of adding the evaluation of season-specific management practice optimization to the research and extension agenda.

\section{Conclusions}

Our study highlights the potential benefit of optimizing crop management for season-specific scenarios based on skillful seasonal precipitation forecasts. A confluence of factors makes that possible: i) IRI PRECIP forecasts were able to successfully forecast below- and abovenormal precipitation scenarios; ii) the length of the growing season allows a wide range of sowing dates; iii) yields are severely affected by water deficit stress regularly and therefore, strategies that allow escaping water stress in critical growth stages and/or incorporating drought tolerant cultivars will result in increased yield. We found that season-specific management practices, selecting maturity groups and sowing dates for specific IRI PRECIP scenarios could result in higher yields than using the dominant management practices applied by farmers which are aligned with a risk-averse strategy. By incorporating this information into the decision-making process and risk management strategy, farmers could potentially improve their adaptation to climate variability and change taking advantage of the availability of a skillful seasonal climate forecast. The approach used in the present study can be used to evaluate seasonal precipitation forecasts across crop producing areas where seasonal climate forecasts are skillful. The results provided here have implications on policy making, since they can help to establish early warnings, and support the design of strategies to mitigate the negative effect of unfavorable weather scenarios.

\section{Author contributions}

Gonzalo Rizzo: Conceptualization; Data curation; Visualization; Formal analysis; Writing - review \& editing. Sebastian Mazzilli: Conceptualization; Writing - review \& editing. Oswaldo Ernst: Conceptualization; Writing - review \& editing. Walter E. Baethgen: Writing review \& editing; Andres Berger: Conceptualization; Writing - review \& editing.

\section{Declaration of Competing Interest}

None.

\section{Acknowledgments}

This project was partially funded on a fellowship from the Instituto Nacional de Investigación Agropecuaria de Uruguay (INIA) granted to the senior author, and by the INIA project \#INIA_CS_48_0_00. Authors wish to thank Deborah Gasso and Cristina Capurro (INIA) for providing access to their field experiment data to evaluate crop model performance. We also acknowledge Mariana Hill, Carlos Clerici, and Martin Dell'Aqua (Ministry of Livestock, Agriculture, and Fisheries of Uruguay) for providing soil and cropping sequence data. We are grateful to FUCREA for providing access to the farmers' database.

\section{Appendix A. Supplementary data}

Supplementary data to this article can be found online at https://doi. org/10.1016/j.agsy.2021.103331. 


\section{References}

Andrade, J.F., Poggio, S.L., Ermácora, M., Satorre, E.H., 2015. Productivity and resource use in intensified cropping systems in the rolling Pampa, Argentina. Eur. J. Agron. $67,37-51$.

Aramburu Merlos, F., Monzon, J.P., Mercau, J.L., Taboada, M.A., Andrade, F.H., Hall, A. J., Jobbagy, E., Cassman, K.G., Grassini, P., 2015. Potential for crop production increase in Argentina through closure of existing yield gaps. Field Crop Res. 184, $145-154$.

Araneda-Cabrera, R.J., Bermúdez, M., Puertas, J., 2021. Benchmarking of drought and climate indices for agricultural drought monitoring in Argentina. Sci. Total Environ. 790,148090

Baigorria, G.A., Hansen, J.W., Ward, N., Jones, J.W., O'Brien, J.J., 2008. Assessing predictability of cotton yields in the southeastern United States based on regional atmospheric circulation and surface temperatures. J. Appl. Meteorol. Climatol. 47, 76-91.

Barnston, A.G., Mason, S.J., Goddard, L., DeWitt, D.G., Zebiak, S.E., 2003. Multimodel Ensembling in seasonal climate forecasting at IRI. Bull. Am. Meteorol. Soc. 84, 1783-1796.

Barnston, A.G., Li, S., Mason, S.J., DeWitt, D.G., Goddard, L., Gong, X., 2010. Verification of the first 11 years of IRI's seasonal climate forecasts. J. Appl. Meteorol. Climatol. 49, 493-520.

Bert, F.E., Podestá, G.P., Satorre, E.H., Messina, C.D., 2007. Use of climate information in soybean farming on the Argentinean pampas. Clim. Res. 33, 123-134.

Bowers, G.R., 1995. An early soybean production system for drought avoidance. J. Prod. Agric. 8, 112-118.

Calviño, P., Monzon, J., 2009. Farming systems of Argentina: Yield constraints and risk management. In: Sadras, V.O., Calderini, D.F. (Eds.), Crop Physiology: Applications for Genetic Improvement and Agronomy. Elsevier, Amsterdam, pp. 55-70.

Calviño, P.A., Sadras, V.O., 1999. Interannual variation in soybean yield: interaction among rainfall, soil depth and crop management. Field Crop Res. 63, 237-246.

Cane, M.A., Eshel, G., Buckland, R.W., 1994. Forecasting Zimbabwean maize yield using eastern equatorial Pacific Sea surface temperature. Nature 370, 204-205.

Carleton, T.A., Hsiang, S.M., 2016. Social and economic impacts of climate. Science 353.

Caviglia, O.P., Sadras, V.O., Andrade, F.H., 2004. Intensification of agriculture in the south-eastern pampas: I. capture and efficiency in the use of water and radiation in double-cropped wheat-soybean. Field Crop Res. 87, 117-129.

Caviglia, O.P., Rizzalli, R.H., Monzon, J.P., García, F.O., Melchiori, R.J.M., Martinez, J. J., Cerrudo, A., Irigoyen, A., Barbieri, P.A., Van Opstal, N.V., Andrade, F.H., 2019. Improving resource productivity at a crop sequence level. Field Crop Res. 235, 129-141.

Crane, T., Roncoli, C., Paz, J., Breuer, N., Broad, K., Ingram, K., 2010. Forecast skill and Farmers' skills: seasonal climate forecasts and agricultural risk Management in the Southeastern United States. Weather Clim. Soc. 2 (2010), 1-2.

de Nóia Júnior, R.S., Sentelhas, P.C., 2019. Soybean-maize off-season double crop system in Brazil as affected by El Niño southern oscillation phases. Agric. Syst. 173, 254-267.

de Nóia Júnior, R.S., Fraisse, C.W., Karrei, M.A.Z., Cerbaro, V.A., Perondi, D., 2020 Effects of the El Niño southern oscillation phenomenon and sowing dates on soybean yield and on the occurrence of extreme weather events in southern Brazil. Agric. For. Meteorol. 290, 108038.

DIEA, 2011. Census 2011. DIEA-MGAP. Last checked November 2021. https://www.gub. uy/ministerio-ganaderia-agricultura-pesca/datos-y-estadisticas/estadisticas/censogeneral-agropecuario-2011-0.

Dong, Z., Wang, H., Li, X., Ji, H., 2021. Enhancement of plant cold tolerance by soybean RCC1 family gene GmTCF1a. BMC Plant Biol. 21, 369.

Ernst, O.R., Kemanian, A.R., Mazzilli, S.R., Cadenazzi, M., Dogliotti, S., 2016. Depressed attainable wheat yields under continuous annual no-till agriculture suggest declining soil productivity. Field Crop Res. 186, 107-116.

Fraisse, C.W., Cabrera, V.E., Breuer, N.E., Baez, J., Quispe, J., Matos, E., 2008. E] Niño-southern oscillation influences on soybean yields in eastern Paraguay. Int. J. Climatol. 28, 1399-1407.

Garnett, T., Appleby, M.C., Balmford, A., Bateman, I.J., Benton, T.G., Bloomer, P., Burlingame, B., Dawkins, M., Dolan, L., Fraser, D., Herrero, M., Hoffmann, I., Smith, P., Thornton, P.K., Toulmin, C., Vermeulen, S.J., Godfray, H.C.J., 2013 Sustainable intensification in agriculture: premises and policies. Science 341, 33-34.

Gaso, D., 2018. Respuesta del rendimiento de soja a la densidad de siembra en ambientes de productividad contrastante. Agrociencia Uruguay 22, 1-12.

Gijsman, A.J., Jagtap, S.S., Jones, J.W., 2002. Wading through a swamp of complete confusion: how to choose a method for estimating soil water retention parameters for crop models. Eur. J. Agron. 18, 77-106.

Giménez, L., 2007. Comportamiento fenológico de diferentes grupos de madurez de soja (Glicine max) en Uruguay. Ubicación temporal del período crítico. Agrociencia 11, $1-9$.

Goddard, L., Barnston, A.G., Mason, S.J., 2003. Evaluation of the IRI'S "net assessment" seasonal climate forecasts: 1997-2001. Bull. Am. Meteorol. Soc. 84, 1761-1782.

Godfray, H.C.J., Garnett, T., 2014. Food security and sustainable intensification. Philos. Trans. Royal Soc. B 369, 20120273.

Grassini, P., van Bussel, L.G.J., Van Wart, J., Wolf, J., Claessens, L., Yang, H., Boogaard, H., de Groot, H., van Ittersum, M.K., Cassman, K.G., 2015. How good is good enough? Data requirements for reliable crop yield simulations and yield-gap analysis. Field Crop Res. 49-63.

Hammer, G.L., Hansen, J.W., Phillips, J.G., Mjelde, J.W., Hill, H., Love, A., Potgieter, A., 2001. Advances in application of climate prediction in agriculture. Agric. Syst. 70, 515-553.
Hammer, G.L., McLean, G., Chapman, S., Zheng, B., Doherty, A., Harrison, M.T., van Oosterom, E., Jordan, D., 2014. Crop design for specific adaptation in variable dryland production environments. Crop. Pasture Sci. 65, 614.

Hansel, D.S.S., Schwalbert, R.A., Shoup, D.E., Holshouser, D.L., Parvej, R., Prasad, P.V. V., Ciampitti, I.A., 2019. A review of soybean yield when double-cropped after wheat. Agron. J. 111, 677-685.

Hollinger, S.E., Ehler, E.J., Carlson, R.E., 2001. Midwestern United States corn and soybean yield response to changing El Niño-southern oscillation conditions during the growing season. In: Impacts of El Niño and Climate Variability on Agriculture. John Wiley \& Sons, Ltd, pp. 31-54.

Hoogenboom, G., Porter, C.H., Sheila, V., Boote, K.J., Singh, U., White, J.W., Hunt, L.A., Ogoshi, R., Lizaso, J.I., Koo, J., Asseng, S., Singels, A., Moreno, L.P., Jones, J.W., 2015. Decision Support System for Agrotechnology Transfer (DSSAT) Version 4.7 (https://DSSAT.net). DSSAT Foundation, Gainesville, Florida, USA.

Jones, J.W., Hoogenboom, G., Porter, C.H., Boote, K.J., Batchelor, W.D., Hunt, L.A., Wilkens, P.W., Singh, U., Gijsman, A.J., Ritchie, J.T., 2003. The DSSAT cropping system model. Eur. J. Agron. 18, 235-265.

Kantolic, A.G., Slafer, G.A., 2001. Photoperiod sensitivity after ${ }^{-}$owering and seed number determination in indeterminate soybean cultivars. Field Crop Res. 72, $109-118$.

Keating, B.A., Herrero, M., Carberry, P.S., Gardner, J., Cole, M.B., 2014. Food wedges: framing the global food demand and supply challenge towards 2050. Global Food Secur. 3, 125-132.

Landman, W.A., Barnston, A.G., Vogel, C., Savy, J., 2019. Use of El Niño-Southern Oscillation related seasonal precipitation predictability in developing regions for potential societal benefit. Int. J. Climatol. 39, 5327-5337.

Lenssen, N.J.L., Goddard, L., Mason, S., 2020. Seasonal forecast skill of ENSO teleconnection maps. Weather Forecast. 35, 2387-2406.

Liang, X.-Z., Wu, Y., Chambers, R.G., Schmoldt, D.L., Gao, W., Liu, C., Liu, Y.-A., Sun, C., Kennedy, J.A., 2017. Determining climate effects on US total agricultural productivity. PNAS 114, E2285-E2292.

Lobell, D.B., Field, C.B., 2007. Global scale climate-crop yield relationships and the impacts of recent warming. Environ. Res. Lett. 2, 014002.

Lobell, D.B., Schlenker, W., Costa-Roberts, J., 2011. Climate trends and global crop production since 1980. Science 333, 616-620.

Martinez, C.J., Jones, J.W., 2011. Atlantic and Pacific Sea surface temperatures and corn yields in the southeastern USA: lagged relationships and forecast model development. Int. J. Climatol. 31, 592-604.

Mason, S.J., Goddard, L., Graham, N.E., Yulaeva, E., Sun, L., Arkin, P.A., 1999. The IRI seasonal climate prediction system and the 1997/98 El Niño event. Bull. Am. Meteorol. Soc. 80, 1853-1874.

Meza, F.J., Hansen, J.W., Osgood, D., 2008. Economic value of seasonal climate forecasts for agriculture: review of ex-ante assessments and recommendations for future research. J. Appl. Meteorol. Climatol. 47, 1269-1286.

Monjardino, M., McBeath, T.M., Brennan, L., Llewellyn, R.S., 2013. Are farmers in lowrainfall cropping regions under-fertilising with nitrogen? A risk analysis. Agric. Syst. $116,37-51$.

Montoya, F., García, C., Pintos, F., Otero, A., 2017. Effects of irrigation regime on the growth and yield of irrigated soybean in temperate humid climatic conditions. Agric. Water Manag. 193, 30-45.

Monzon, J.P., Sadras, V.O., Abbate, P.A., Caviglia, O.P., 2007. Modelling management strategies for wheat-soybean double crops in the south-eastern pampas. Field Crop Res. 101, 44-52.

Olesen, J.E., Trnka, M., Kersebaum, K.C., Skjelvåg, A.O., Seguin, B., Peltonen-Sainio, P., Rossi, F., Kozyra, J., Micale, F., 2011. Impacts and adaptation of European crop production systems to climate change. Eur. J. Agron. 34, 96-112.

Podestá, G., Letson, D., Messina, C., Royce, F., Ferreyra, R.A., Jones, J., Hansen, J., Llovet, I., Grondona, M., O’Brien, J.J., 2002. Use of ENSO-related climate information in agricultural decision making in Argentina: a pilot experience. Agric. Syst. 74, 371-392.

Potgieter, A.B., Everingham, Y.L., Hammer, G.L., 2003. On measuring quality of a probabilistic commodity forecast for a system that incorporates seasonal climate forecasts. Int. J. Climatol. 23, 1195-1210.

Rattalino Edreira, J.I., Mourtzinis, S., Conley, S.P., Roth, A.C., Ciampitti, I.A., Licht, M. A., Kandel, H., Kyveryga, P.M., Lindsey, L.E., Mueller, D.S., Naeve, S.L., Nafziger, E., Specht, J.E., Stanley, J., Staton, M.J., Grassini, P., 2017. Assessing causes of yield gaps in agricultural areas with diversity in climate and soils. Agric. For. Meteorol. 247, 170-180.

Rattalino Edreira, J.I., Mourtzinis, S., Azzari, G., Andrade, J.F., Conley, S.P., Lobell, D., Specht, J.E., Grassini, P., 2020. From sunlight to seed: assessing limits to solar radiation capture and conversion in agro-ecosystems. Agric. For. Meteorol. 280, 107775.

Ritchie, J.T., Crum, J., 1989. Converting soil survey characterization data into IBSNAT crop model input. In: Symposium Organized by the International Society of Soil Science (ISSS), Wageningen (Netherlands), 22-26 Aug 1988. Pudoc.

Rizzo, G., Monzon, J.P., Ernst, O., 2021. Cropping system-imposed yield gap: proof of concept on soybean cropping systems in Uruguay. Field Crop Res. 260, 107944.

Ropelewski, C.F., Halpert, M.S., 1987. Global and regional scale precipitation patterns associated with the El Niño/southern oscillation. Mon. Weather Rev. 115, 1606-1626.

Schoving, C., Stöckle, C.O., Colombet, C., Champolivier, L., Debaeke, P., Maury, P., 2020. Combining simple Phenotyping and Photothermal algorithm for the prediction of soybean phenology: application to a range of common cultivars grown in Europe. Front. Plant Sci. 10, 1755. 
Tito, R., Vasconcelos, H.L., Feeley, K.J., 2018. Global climate change increases risk of crop yield losses and food insecurity in the tropical Andes. Glob. Chang. Biol. 24, e592-e602.

van Bussel, L.G.J., Grassini, P., Van Wart, J., Wolf, J., Claessens, L., Yang, H.,

Boogaard, H., de Groot, H., Saito, K., Cassman, K.G., Van Ittersum, M.K., 2015. From field to atlas: Upscaling of location-specific yield gap estimates. Field Crop Res. 177, 98-108.

Van Ittersum, M.K., Cassman, K.G., Grassini, P., Wolf, J., Tittonell, P., Hochman, Z., 2013. Yield gap analysis with local to global relevance-a review. Field Crop Res. 143, 4-17. van Wart, J., Grassini, P., Cassman, K.G., 2013. Impact of derived global weather data on simulated crop yields. Glob. Chang. Biol. 19, 3822-3834.

Vitantonio-Mazzini, L.N., Gómez, D., Gambin, B.L., Mauro, G.D., Iglesias, R., Costanzi, J., Jobbágy, E.G., Borrás, L., 2021. Sowing date, genotype choice, and water environment control soybean yields in Central Argentina. Crop Sci. 61, 715-728.

White, J.W., Hoogenboom, G., Wilkens, P.W., Stackhouse, P.W., Hoel, J.M., 2011. Evaluation of satellite-based, modeled-derived daily solar radiation data for the continental United States. Agron. J. 103, 1242-1251.

Zanon, A.J., Streck, N.A., Grassini, P., 2016. Climate and management factors influence soybean yield potential in a subtropical environment. Agron. J. 108, 1447-1454. 